\title{
Removal of the nonconformities in the drug boxes packaging industry
}

\author{
Emilia Bălan*, and Florin Marian Dobrea \\ Politehnica University of Bucharest, Machines and Production Systems Department, Splaiul \\ Independenței 313, District 6, Bucharest, Romania
}

\begin{abstract}
The paper presents the specific quality aspects of cardboard drug boxes (folding boxes) used as packaging in pharmaceutical industry. The types of defects and nonconformities that occur during offset printing and finishing of the packaging products are being identified and analyzed, such as: differences in color printing, scratches on the printed sheets, cracks during creasing, unparalleled gluing in respect to the closing flaps, ungluing, successive drug boxes stick to each other. The paper also focuses on aspects regarding the nonconformities removal of the drug boxes by establishing a control plan and preventive and corrective methods applicable in different technological stages of the production flow. Monitoring and analyzing activities for quality improvement of the drug boxes, in accordance with the quality specifications required by customers were performed for 20 months on a production line with Heidelberg machines. Nonconformities considered in this paper are also encountered in advertising printing.
\end{abstract}

\section{Introduction}

The materials used in packaging are paper, cardboard, wood, plastics or textiles, metal, glass etc. They are used for packaging products obtained in different industrial fields: pharmaceutical and cosmetic industry, food and beverage industry, consumer goods, industrial machinery and equipment. The package protects products and isolates them from the environment, preparing them for transport, warehousing, logistics, sale, in the end reaching the consumer.

Printing the packages and labels (included or made separate from the packaging product) is a field of activity continuously growing. The European Union has allocated a budget of 454 billion euros in 2014-2020 for Southern East Europe, which is situated on the fourth place in the packaging industry. The incomes obtained from printing packages and labels were of approximately 76 billion euros in 2015 [1].

Currently, paper and cardboard packaging are used widely in various industries because they can be reused and recycled. In Europe, their recycling rate reached $72 \%$ from a consumption of 80 million tons in 2014 [1]. They can also be incinerated for energy recovery and most of them are biodegradable.

\footnotetext{
*Corresponding author: emilia.balan59@yahoo.com
} 
Paper and cardboard are made as sheets. They can be differentiated by thickness, the type of fiber pulp (bleached/unbleached, separate mechanical/chemical, fiber first use/recycled), the amount of the fiber, after treatment and additives used in the preparation of the pulp, but also by manufacturing processes (arrangement into layers with other ingredients, the number of layers or laminating operations, etc.). The characteristics of paper and cardboard must provide both the necessary technical performance of the packaging, as well as its visual aspect. This can be achieved by using printing and finishing processes of the packaging [2$3]$.

In packaging, print runs are large and very large. The strategy of product quality assurance of specialized organizations should be oriented towards identifying and eliminating defects and nonconformities that occur during offset printing and finishing packaging products because they directly affect the performance of the organization [4].

Frequently, the following major nonconformities are found in packaging [2, 5-8]: differences in color after printing, scratches on the printed sheets, cracks during creasing, unparalleled gluing in respect to the closing flaps, ungluing, successive packages stick to each other.

\section{Case study}

The experimental work presented in this paper was performed in a company with a significant portfolio of clients. The company is certified for integrated management systems according to SR EN ISO: 9001: 2015, 14001: 2005, 18001: 2008.

According to their quality documented information, for treating a nonconforming product, a number of activities should be undertaken, these being included in a strategic plan for ensuring the products quality. Their aim is to control the nonconformities effect, to limit their occurrence and to remove their recurrence [9].

\subsection{Heidelberg production line}

The experimental part was performed on an integrated Heidelberg production line, consisting of equipment which works in a semiautomatic-automatic system: flat offset printing, hot thermal sheet laminating, flat-bed die-cutter and off-line gluing system. The print runs can vary between $500-5,000,000$ products per model, with an efficiency of up to 60,000 products per hour.

The production line consists of: • Computer-to-Plate - Suprasetter A74; • offset printing machine - Heidelberg Speed Master SM74-5P2 LH; • cutting machines - Heidelberg Polar 92NT and 78XT; $\bullet$ hot thermal film laminating machine - Laminator; • flat-bed die-cutter machine - Heidelberg Varimatrix CS 82; • cylindrical die-cutter machine - Heidelberg Cylinder; • gluing machine - Heidelberg Easygluer 100.

\subsection{Specific nonconformities of printed drug boxes}

The aim of this study was to identify defects and nonconformities of the printed drug boxes, to determine the causes of their appearance and to propose preventive and corrective methods applicable in different technological stages of the production flow. Monitoring and analyzing activities for quality improvement of the drug boxes in accordance with the quality specifications required by customers were performed for 20 months (December 2014 February 2016). During this period, $14,237,650$ pieces of drug boxes were produced. Print runs with nonconformities totaled 2.652 million pieces, but only 47,058 pieces have nonconformities. They were found in 49 orders. 
Nonconformities encountered due to the use of $\boldsymbol{G C 1}$ cardboards (coated paper with mixed pulp and white back; chemical and mechanical pulp bleaching; codification according to DIN 19303:2011 standard) are shown in Table 1.

Table 1. Nonconformities generated by improper characteristics of cardboard.

\begin{tabular}{|l|l|l|}
\hline \multicolumn{1}{|c|}{$\begin{array}{c}\text { Characteristic of } \\
\text { cardboard }\end{array}$} & \multicolumn{1}{|c|}{ Nonconformity generated } & \multicolumn{1}{|c|}{ Place in technological flow } \\
\hline $\begin{array}{l}\text { Cardboard excessive } \\
\text { curving }\end{array}$ & Blocking the equipment and \\
\cline { 1 - 2 } $\begin{array}{l}\text { Cardboard with variable } \\
\text { porosity or thickness }\end{array}$ & $\begin{array}{l}\text { On printing machine, hot thermal } \\
\text { film laminating machine, die- } \\
\text { cutter machine, gluing machine }\end{array}$ \\
\cline { 1 - 2 } $\begin{array}{l}\text { Cardboard } \\
\text { electrostatically charged }\end{array}$ & $\begin{array}{l}\text { Poor quality of the printing } \\
\text { process }\end{array}$ & On printing machine \\
\hline $\begin{array}{l}\text { Cardboard with variable } \\
\text { roughness }\end{array}$ &
\end{tabular}

GC1 cardboards are supplied by four manufacturers: Avanta Prima and Charter Integra (Europe), Ningbo Fold and Zenith (Asia). Even if when contracting the cardboard suppliers they provide quality certificates, in practice many deviations from the technical characteristics occur. This generates nonconformities on the technological production flow.

Preventive measures implemented to avoid such nonconformities were:

- renegotiation with customers in order for them to accept a superior quality of the raw materials;

- identification of other potential suppliers of cardboards;

- requesting of quality specifications of cardboards for each run supplied.

Nonconformities frequently occurring due to the offset printing were as follows: variation of the color density; picking of the cardboard fibers or picking its coating layer due to improper transfer of inks (Fig. 1); scratches on the printed sheet (Fig. 2); apparition of spots due to damage on the printing plate surface (Fig. 3).

The corrective measures implemented in order to remove these nonconformities were:

- guiding sticks have been ordered and were mounted in the removal part of the printing machine - in this way the cardboard sheets is no longer touching the crossbar;

- replacement of printed plates, which were scratched.

The major nonconformity that may occur after varnishing is picking the varnish of the printed sheet (Fig. 4). Protective coating of the varnish is recommended to be done in order to avoid unnecessary inconvenience that may occur in further processing the printed material (due to insufficient time allowed for the ink to dry) and for giving an attractive aspect of the final product.

The implemented corrective measures to overcome this nonconformity were:

- performing the settings for applying the varnish layer on the printed sheet more carefully;

- adjusting the temperature of the drying oven or the thickness of the varnish layer.

Nonconformities occurring in the die-cutting operation have two main causes [6]:

- improper behavior of cardboard during compression-folding operations (the compression of cardboard depends on its elastic-plastic characteristics);

- mismatching mold-puncheon used to crease (improper pressure on cardboard by misuse of creasing groove width).

The appearance of cracks on the creases of the boxes is the nonconformity generated by these two reasons (Fig. 5 and Fig. 6). Figure 7 illustrates the microscope image of nonconformities arising when using nonconforming creases. Nonconformities due to the improper use of the fiber of the cardboard are shown in figure 8. 


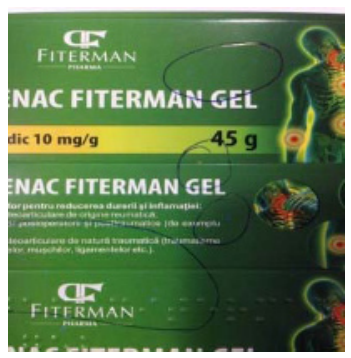

Fig. 1. Nonconformity "lint" due to the improper transfer of inks.

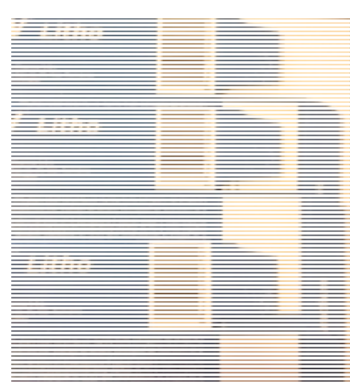

Fig. 4. Picking of the varnish from the printed sheet.
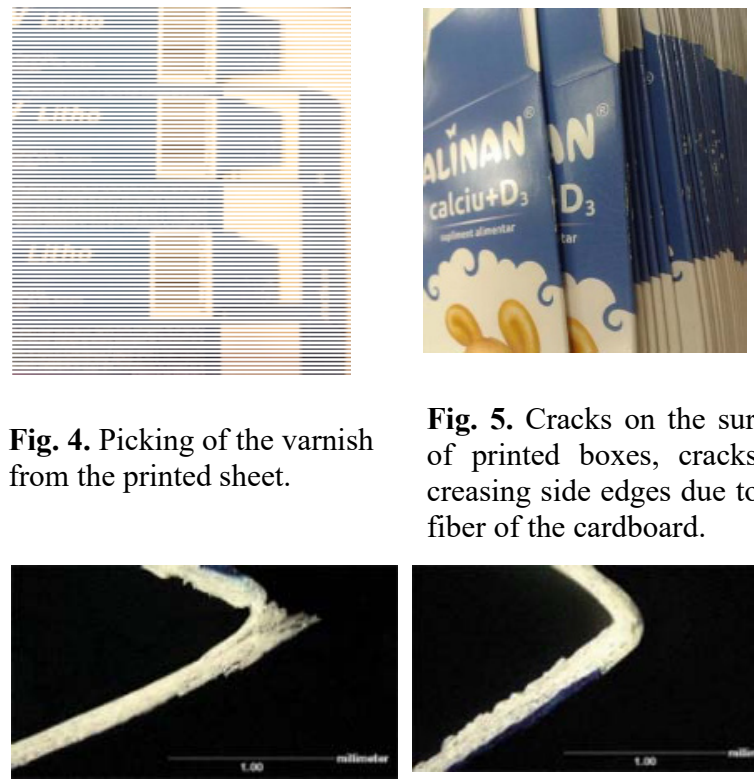

Fig. 2. Scratches on the printed sheet.
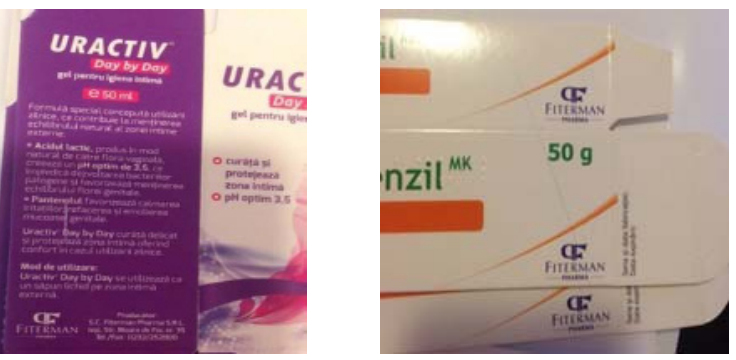

Fig. 3. Stripes due to the damage on the printing plate surface.

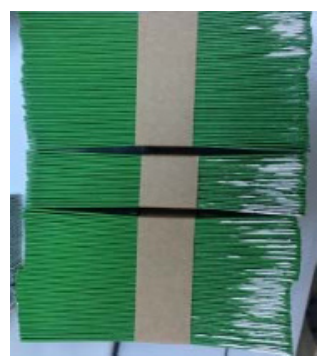

Fig. 5. Cracks on the surface of printed boxes, cracks on creasing side edges due to the fiber of the cardboard.

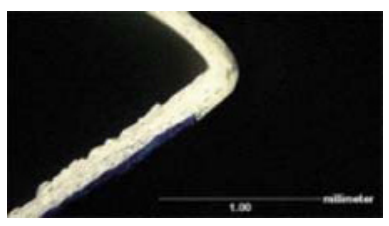

Fig. 6. Cracks on the surface of printed boxes, cracks on creasing side edges due to mold-puncheon assembly.

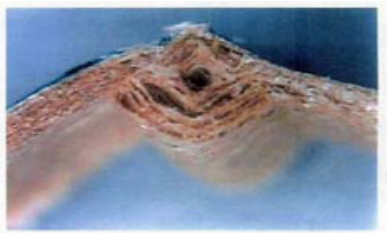

Fig. 7. Nonconformities arising when using nonconforming creases

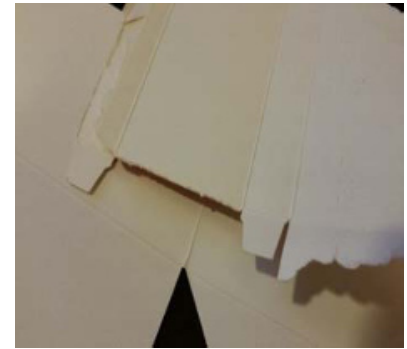

Fig. 8. Nonconformities due to the improper use of the fiber of the cardboard.
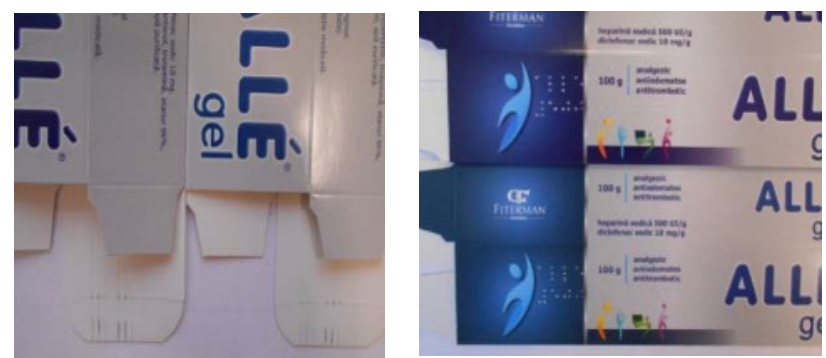

Fig. 9. Traces of ink on the unprinted surface (inside) of the drug boxes.

Taking into account the potential causes for these nonconformities, upon identifying them, a number of tests were performed: 
a. Die-cutting tests on the same type of GC1 cardboard provided by the four producers. After completing the die-cutting of the four cardboard specimens under identical conditions, the following results were obtained:

- on Avanta Prima and Charter Integra cardboard - there were not detected essentially cracks after creasing;

- on NingBo Fold and Zenith cardboard - cracks persisted, blocking the major variations of the main characteristics (thickness of cardboard $[\mu \mathrm{m}]$ and specific weight $\left[\mathrm{g} / \mathrm{m}^{2}\right]$ ) of the same run; major variations were more than $+/-5 \%$.

b. Die-cutting tests for the same GC1 cardboard from NingBo Fold in two types of diecutter machines. There was used a flat-bed die-cutter machine, respectively a cylinder die-cutter machine. The cardboard was fed on machines in two different ways: • oriented on fiber direction; $\bullet$ oriented versus fiber direction.

In this study, the occurrence of cracks was observed on the creases perpendicular to the feed direction of the cardboard only for the cylinder die-cutter machine; the cardboard was fed against fiber direction.

c. Die-cutting tests for the same GC1 cardboard from NingBo Fold on a flat-bed diecutter machine. In this study, there were used various thicknesses of grooves creases (direct and versus creases). The following aspects have been observed:

- the cracks did not appear when the thickness of grooves crease was decreased, but the quality decreased (the depth of creasing);

- according to the thickness of the cardboard used the recalibration of the die-cutting form with versus creases type "long life" was required;

- a new die-cutting technology involving milled versus creases (Pertinax puncheon) was used; it was obtained a more accurate die-cutting and creasing throughout the entire process.

Corrective and preventive measures applied in order to avoid generating these nonconformities were:

- the die-cutter workers were retrained on how to use the versus crease correlated with the thickness of cardboard, but also correlated with the fiber direction;

- the use of Pertinax puncheon in the die-cutting process became the new norm.

Following these actions, the quality problems such as cracks of drug boxes (cracks due to die-cutting and creasing process) have been decreased with more than $80 \%$.

In the gluing stage of the boxes, the following nonconformities occurred:

1. poor gluing of the drug boxes;

2. successive boxes stick to each other;

3. occurrence of traces of ink on the surface of the boxes (Fig. 9).

The corrective and preventive measures applied were the following:

1. the glue lubrication with a rotating disk was removed, using only the glue lubrication with a digital controlled nozzle;

2. the boxes that remained on the line between the folding-gluing zone and the pressing zone were eliminated if the machine was stopped by accident or deliberately.

Regarding the third nonconformity identified, the gluing equipment producer was consulted and it has been found that the gates, which limited the supply of the machine, were positioned in the same area with the braille codes. Therefore, the ink on the braille points (embossed) was transmitted to the strings of the next package. Consequently, it was proposed to change the position of the gate which limited the supply on a side where there is no braille code (embossed). Thus, the ink transfer was removed.

In addition, the following corrective measures were applied: $\bullet$ reducing the power of vacuum; • increasing the separation distance between the box and the conveyor belt.

A preventive measure proposed was to disassemble and clean the conveyor belts weekly. 
In figure 10 there is presented the report of changes, in percentage, of nonconformities identified on the production line for the 49 orders during the monitoring period.

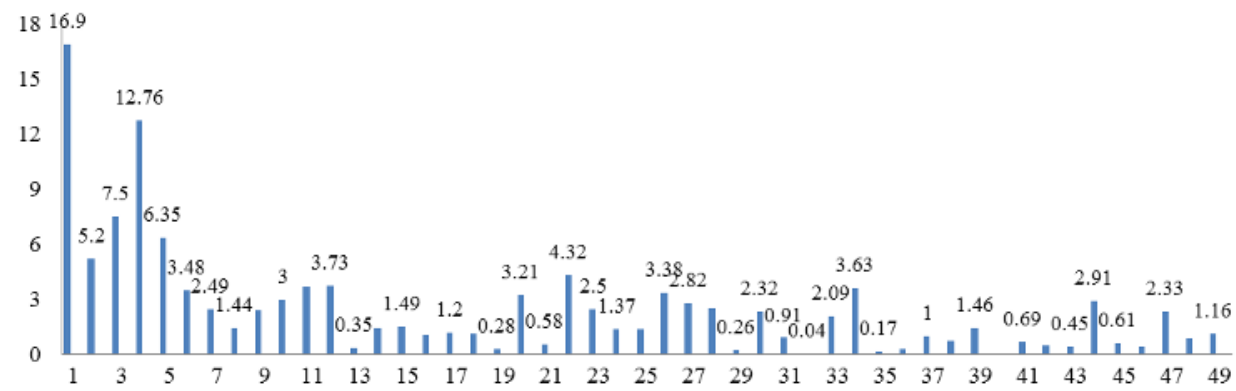

Fig. 10. Evolution of nonconformities of drug boxes.

\section{Conclusions}

This paper presented specific quality aspects of printed cardboard drug boxes. These may not always be aligned with the quality specifications required by customers.

All nonconformities that occurred during the launching in manufacturing of 49 orders have been studied and analyzed. It was considered that all these nonconformities are significantly affecting the quality of the final product. The originality of the presented research consists in the solutions that were proposed by the authors in order to prevent the amount of nonconformities.

The made research has led to the following conclusions: - a great number of nonconformities was generated at the beginning of the monitoring period, but the situation gradually decreased due to the implementation of corrective and preventive measures $\bullet$ the design of the removal part of the printing machine needs to be improved; $\bullet$ the use of Pertinax puncheon in the die-cutting process became the new norm; $\bullet$ the glue lubrication must be done with a digital controlled nozzle.

Using a high grade cardboard on the production line proved to be the best solution for removing the nonconformities that occur in the manufacturing process of drug boxes. The company has changed its procedure for selecting the suppliers of raw materials in consequence.

\section{References}

1. D. Calin, Print Magazin, 65, (2015) - http://www.print-magazin.ro

2. D. Twede, S.E. Selke, D.P. Kamdem, D. Shires, Cartons, crates and corrugated board: handbook of paper and wood packaging technology (DEStech Publications, Inc., 2014)

3. www.sappi.com

4. A. Nagyova, M. Palko, H. Pacaiova, IQC, pp. 33-42, (2015)

5. G. Müller, Paper Technology, 52 (3), pp. 24-25, (2011)

6. E.D. Demaine, Folding and Unfolding, $\mathrm{PhD}$ thesis, University of Waterloo, Ontario, Canada, (2001)

7. B. Frank, Packaging Technology and Science, 27 (2), pp. 105-128, (2014)

8. B.Y. Sun, Y.L. Li, Packaging Engineering, 4, 019, (2008)

9. V. Bendic, D. Tilina, WSEAS, 7, pp. 133-136, (2010) 